\title{
The Role of Urban Advertising in Quality of Urban Land Scape
}

\author{
MAHSA ZAMIRI \\ Lecturer in Urban Planning, University Of Bojnord, Bojnord, Iran. \\ http://dx.doi.org/10.12944/CWE.11.Special-Issue1.03
}

(Received: July, 2016; Accepted: August, 2016)

\begin{abstract}
Urban advertising is one of the most important principals of advertising knowledge and one of the factor elements of urban landscape in human habitation as it is known an impartible part of urbans framework and the most significance part of commercial acts are appertained to this subject. Present study that in method is applicable, by using of description method work on urban advertising and its incident in Imam St. of Urmia center of West Azerbaijan (as the most important commercial and actual axle in this city) then by using of analyzing method and surveying on rules and regulations and also the visit of case study, outcome information were processed to use of analyze method SWOT proposed administrant solutions for improvement of civil advertising in Imam St. of Urmia. According to encourage of using adaption equipment advertising, deleting the impermissible publicities and preventing of accession of them and consider to needs of small jobs owners and also environmental temporary advertising are proposed as guidelines proposals.
\end{abstract}

Keywords: urban space, urban advertising, urban landscape

\section{INTRODUCTION}

21 century is the century of information revolution and the media variety is one of the properties of these times. In a time when communication period known as his propaganda presented as an advanced knowledge and as an important tool for economic purposes and has a lot of influence in the labor market. Now imagine a city without billboards and advertising signs and symbols is not possible and urban advertising is an inseparable part of the layout of cities. Urban advertising is already known and some even believe sometimes a problem to remove it from the city, but it seems proper use of urban advertising not only visual beauty and diversity of urban space but it is a source of revenue for municipalities to spend optimize their environments and provide better municipal services. Urmia as well as other cities of our country generally has consequences on the urban landscape itself is facing the development of urban advertising. Although advertising is one of the ways to beautify the urban landscape, sometimes regardless of the size of their ability aesthetic of urban spaces to advertising use. That is why it seems necessary to identify desirable characteristics of outdoor advertising in urban area, current problems identified at the level of the city and steps to be taken to fix them. The purpose of this article is to examine the issue of urban advertising in the Urmia, Imam St. has been looking at the commercial center, so that the proposals in the strategic framework to enhance quality and improve the view of the street be provided.

\section{literature}

Despite the simplicity issues in urban areas, to some extent remains unknown. The desirable urban environment, the space qualifying vitality, motility and vitality that is necessary for a good urban landscape. The main objective of urban elements are expertly crafted to be ensured that its impact on the senses. Square and street are known as the two basic elements of urban space. Among the most important town streets and public spaces are 
the most effective.in fact the importance of street is from several directions: an important part of the city is dedicated to streets and public places, the streets of the city are known as the main ingredient and connecting spaces and urban activities together, the streets are as a symbol of cultural and urban design as the most important tool. According to Gordon Cullen definition of the urban landscape, urban landscape art visual and structural integrity to set up the buildings, streets and places that make up the urban environment. Throughout cities history, streets have provided a favorable environment for advertising. Objective and subjective signs along the way, so as to be perceptible to the citizens, which makes their citizen status has a feeling about his history or history of someone lived there. Chaos and confusion in the outdoor advertising visual identity gives a distinct and unique urban space. So pay attention on elements such as signs in urban design can greatly help to strengthen the sense of place and identity. So advertising known as the effective element on the urban spaces and this point make most necessary and important work on this science problem. But, unfortunately, until now there is no serious and systematic study on this purpose.

Advertising or propaganda is a show that presented by a person or institute by purpose of influence on the thoughts and acts of people. All of the urban elements side the correct signs can help to enforce the identity and economic vitality and change it to an active and strenuous place.
Although many known the emerge of advertisement simultaneously with the advent of the mass media, but since the industrial revolution advertising as a marketing communication tool evolved to become an art and a science.

According to the importance of advertising in economic and social affairs, to introduce a variety of promotions for goods and products used by companies and producers. Citizens in neighborhood and life environment are faced to urban advertising. These kinds of advertising consists of graffiti, painting, design and installation poster, announcements and notices, statues and inscriptions and various topics in the field of cultural, social, political, economic and commercial that happened in the city by state organs, public institutions, associations and companies as well as citizens can be done. Urban advertising divided to two categories: fixed and fixed. Signs, billboards and graffiti are part of urban fixed advertising and example of an urban mobile ads is bus ads. Totally signs and urban status are used as making relation. The main goals of signs and symptoms, regulation and classification and foster understanding in the urban environment. The establishment of operational rules adopted by the municipality beautify the city of Urmia generally the symptoms can be divided into six main groups: orientate, inform, guide, identify, express or terms and beauty. To be effective urban advertising medium must have certain characteristics to be considered in designing or evaluating them. Some features

Table 1: The features expected of an urban advertising

Readability

Strengthening face and urban identity Harmony

Hierarchy and balance in the environment
Good height and size of signs and letters

Simple and rational utilization of letters and images

The limited number of messages

According to the history of the city, the existing urban fabric, prospects and future role of city

Coordination between and among the different boards and panels and other elements of the urban environment Given the signs and symptoms city as part of the urban furniture

Giving priority to the warning signs and road signs Concerning the relationship between symptoms and localization needs, expectations and ability to execute them 
must be considered in designing or evaluating them. Readability, strengthening face and urban identity, harmony and respect for hierarchy and are included in the balance (table1).

Advertisements at different levels needs guidelines, criteria and parameters of its own because the exquisite and beautiful landscape in increased participation, collaboration and accountability between citizens law and even the support of the municipal regulations; but confusion and visual pollution in the city's residents that afflicts not only the soul but also prevent them from collaboration and partnership. Urban advertising if done correctly and in a manner undergraduate and thought can help to beautify the city and a flourishing economy and production is higher. Outdoor advertising in the past decade have greatly changed in shape and its quantity. That's why different standards in the advertising environment have greatly changed in shape and its quantity. But in our country less attention has been given to them that utilizes the principles and criteria can be of field, beautiful and safe.

In section B of Article 137 of the Third Development Plan of the Islamic Republic of Iran organizing and optimizing the landscape of the city in order to the needs and demands of the citizens is a necessity. Regulatory factors and beautify the municipality is in charge of urban advertising in most cities is to develop criteria and guidelines, after the Ministry of Culture and Islamic Guidance, on how the campaign is monitoring. The beautification Organization of Tehran in Iran was created in 1370.
This organization in order to achieve their goals, to develop regulations regulate advertising in Tehran.

\section{Background of the study}

So far in our country about the advertising industry in the field of view of the impact of urbanization and urban advertising landscape street as an urban space, has been done. In one example of this issue in Iranian cities, in a study that was conducted in 1389, the municipal advertising has been investigated in Chahar Bagh St. of Isfahan and compare with urbanization principles and criteria. In present study proposed something about condition and the manner of using of these signs by studying on condition of signs and considering natural characteristics of Chahar Bagh St. and also culture and historical background of city.

In the article that proposed in 2006, three questions are asked: first, which factors caused to raise the environmental advertising in this era? Second, how changing in form of environmental advertising effect on the manner of using of public town spaces and public use of them? Third, how can trend the visual landscape environment to be popular and predict every harmful effect of environmental advertising?

In the study that done in Japan, three areas of Osaka were selected as case study and the condition of environmental advertising and urban landscape was studied: the commercial zone of city direct to main street, playground in axle of citizen shopping and in main square train station. Also in this study more of all factors the effect of color in

\begin{tabular}{|c|c|c|c|}
\hline Strengths & Weakness & Opportunities & Threats \\
\hline $\begin{array}{l}\text { Existence of a law } \\
\text { for ordering } \\
\text { urban advertising } \\
\text { in Urmia } \\
\text { Existence of } \\
\text { standard } \\
\text { equipment and } \\
\text { suitable for } \\
\text { advertising }\end{array}$ & $\begin{array}{l}\text { Limitation capacity of urban } \\
\text { advertising equipment } \\
\text { Original Un-organizing of } \\
\text { frame and form of advertising } \\
\text { signs installation } \\
\text { Misuse of urban equipment } \\
\text { for advertising } \\
\text { Don't use of equipment in } \\
\text { urban advertising }\end{array}$ & $\begin{array}{l}\text { Existence of set of } \\
\text { special standards } \\
\text { and laws for urban } \\
\text { advertising }\end{array}$ & $\begin{array}{l}\text { Don't regarding the citizen's } \\
\text { rights and don't general } \\
\text { awareness about importance } \\
\text { of environmental advertising } \\
\text { in urban landscape Only } \\
\text { mime of methods and } \\
\text { advertising patterns of other } \\
\text { cities and countrieslgnoring } \\
\text { of capacities for advertising } \\
\text { small jobs and temporary } \\
\text { advertisingenvironment }\end{array}$ \\
\hline
\end{tabular}


urban environment is studied and effect of every color on the intellectual vision of citizens from urban environment.

\section{METHODOLOGY}

In this study methodology in study process is problem solving and description (written and pictorial). The method is descriptive-analytic and clearly is evaluation. Observation and square visions were the basic tools of study and besides them used of documented study and librarian. Also at the end by using of strong and weak table and opportunities and threats (SWOT) there were some suggestions in frame of improvement and gradation of quality of
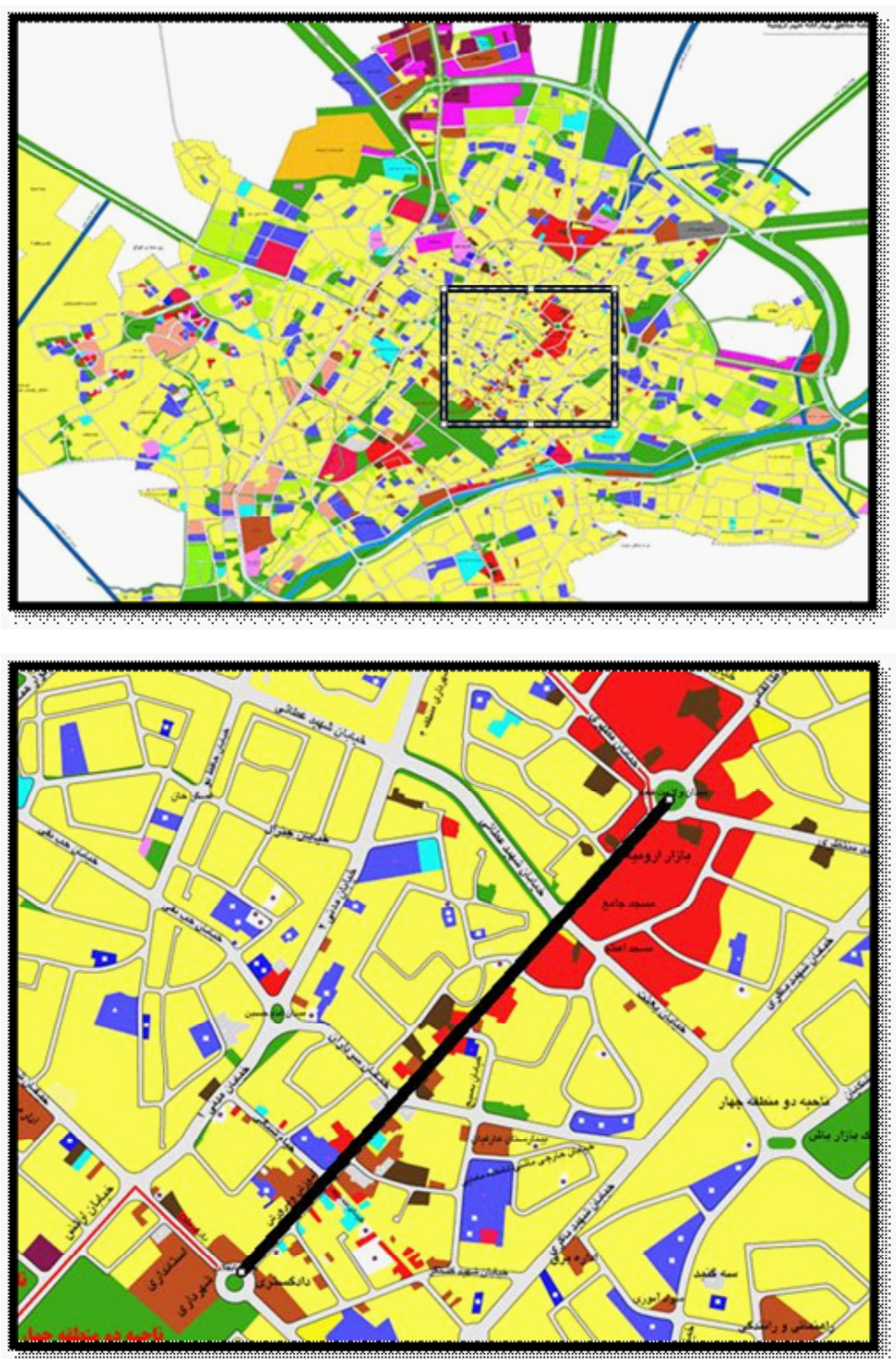

Fig. 1: Case study in Urmia Source: Urmia;s Municipality 
urban landscape in Imam St. Urmia by accordance to urban advertising is proposed.

\section{Case study area}

Urmia is located in a wide plain and near the Urmia Lake in the west of Iran and is the center province. Urmia had more of half million people. Corpus in this study is Imam St. between Inghilab Sq. (lialat) and Velayat-e-faqih (center). The path studied is a main part of old Urmia. This path that connect the army house to the main and old market, is the first modern street that was built in the first Pahlavi era. This street divided market of city into east and west parts. Imam St. Of Urmia after the market lost its original function, known as the city's business center. Also this street has the city's most important role of access between multiple locations. Because commercial activity that is dominant in the streets, nearly fifteen hours a day of activity seen in this axis. 10 to 1 a.m. and 5 to 9 p.m. are the most active hours

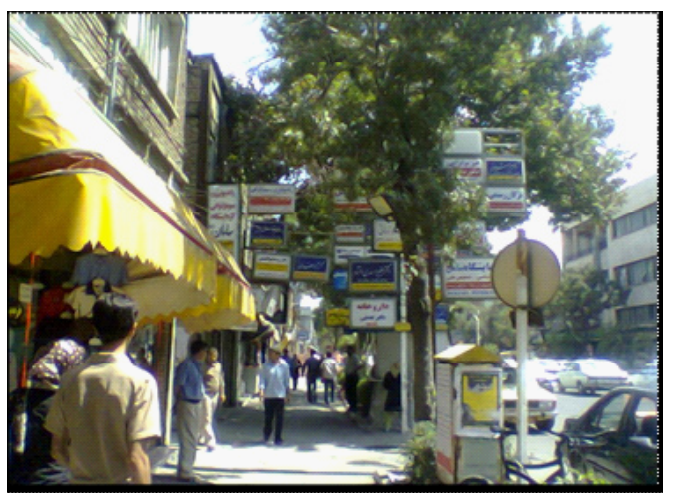

Fig. 2: Medical signs Sourse: authers

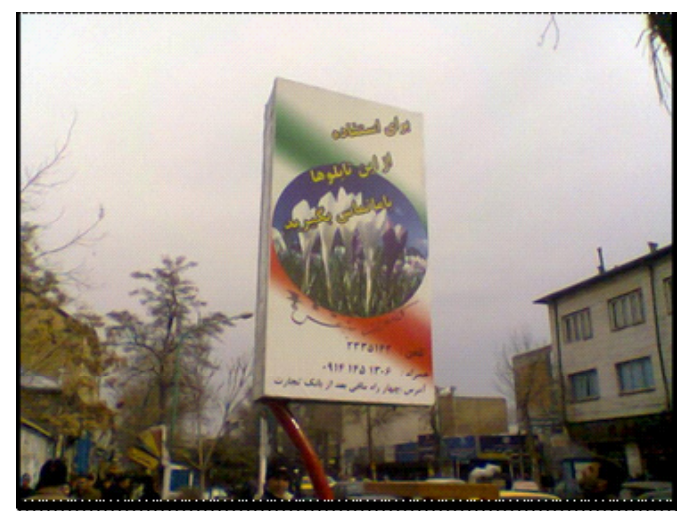

Fig. 4: Equipments for urban advertising Sourse: authers in this space. And in the middle of the day is in the low mobility. Because of services that are offered in the streets of every class and group pf people in this space and every of them wants varied needs and wants. From elements of urban landscape in Imam St. can point to entrance of main markets, great mosque and Sardar mosque and also administrative buildings as educational system and transmission.

\section{Urban advertising in Urmia}

In Urmia the beautification organization is the responsible of supervision on the advertising of urban advertising. This organization prepared some programs for improving the condition of urban advertising. For this, there are new laws passed that according them all organizations and instructors and people should have permitted for their advertising signs. Also the installation of advertising billboard is done by supervision and place fixation by this organization and advertising clubs. Until 1384 traffic

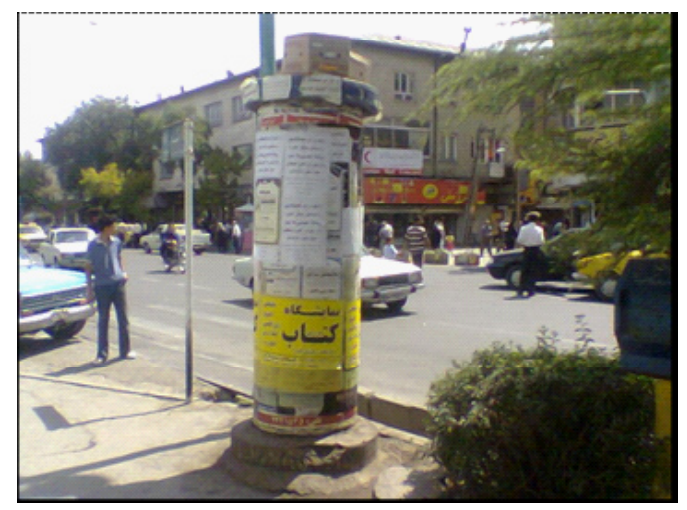

Fig. 3: Equipments for urban advertising Sourse: authers

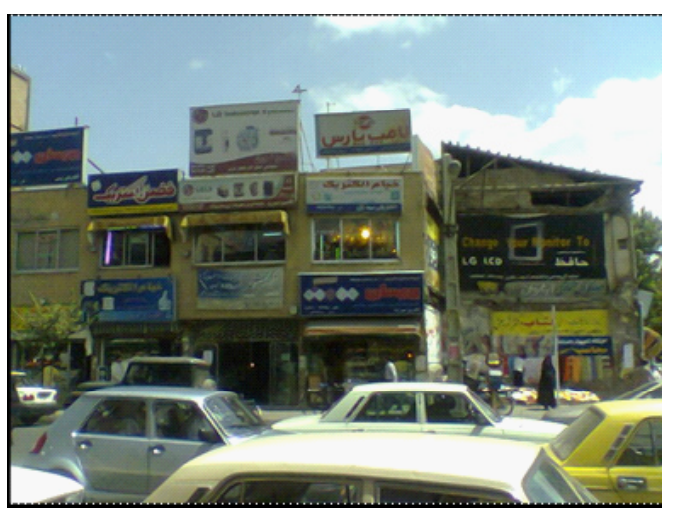

Fig. 5: Visual disturbance Sourse: authers 
signs were under supervision of this organ but from that year until now this duty is on the traffic office. Beautification organization at the end of 1384 codified a law for ordering the urban advertising in Urmia that this law was administrative by beautification organization in 1385. In this law urban advertising there are eight parts: sign of control store (signs of job and activity); sign of un-residential (educational, medical, remedial); sign of mall; sign of building roof; signs of medicine; billboard; installed sign of overpass and wallboard (one form statue advertising that are installed on the wall of pavement and walls impending to main street).

Various methods of advertising used in Urmia, including referrals boards, billboards, traffic signs, temporary advertising medium, advertising on bus stops and the bus advertising. Also installation of leaflets, paper and banners and wall-to-door advertising practices common in homes and public places in Urmia that harm to the face of city from vision view. This intensity is higher in the central and commercial Urmia so that no there is no wall empty of advertising. Although a few years urban advertising in major cities, including Urmia, municipalities have been monitored more closely and beautification organization responsible for research, design and installation of the signs, but in spite of all the positive efforts made, outdoor advertising system and logical unit and the application is not advertising and design and coordination has been poor with the urban environment. In figures 2-5 shows some samples of these.

\section{Conclusions, results and suggestions}

Taking into account the characteristics of urban advertising desirable as well as review existing laws and regulations in Urmia and field observations range of strength, weaknesses, opportunities and threats of the urban landscape in this area identified is expressed in table SWOT. This table help to researchers with an accurate understanding of current issues, the strengths and opportunities that lie ahead, to meet their existing weaknesses and threats. Although SWOT method is generally known and is used as a qualitative method but there methods for quantifying and documented to strength results. By using of quantifying can simplified the model, extract important guidance factors and then codified them.
Totally the surveys shows that most of laws and characteristics of urban advertising is not in the streets. For this reason it is necessary to do a fast and exact action for improving and modifying the current condition.

According to table 2 we can suggested followings for gradating the quality of urban landscape of Urmia: Encouragement for using of suitable advertising equipment

It is obvious that because of unsuitable locating or not acceptable price of equipment for urban advertising in Urmia, there is no interesting for costumers. By solutions as considering suitable place for installing urban advertising equipment, use of suitable equipment for training advertising and urban information and map, logical pricing and considering to signs and their beautifying, costumers prefer the urban advertisings more.

\section{Deleting the illegal advertising and prevention} of access to them

Wall cleanness and completely applying the law in Urmia about environmental advertising, use of a coordination and effective system for signs and urban symbols in installation place, considering cultural and continental characteristics in designing advertising equipment, setting cash fine for conflict to criminals and awareness of citizens about physical effects of ugly landscape are some solutions according to this subject.

Consider to needs of small jobs owners and temporary advertising environment

Don't essence of spaces and necessary and enough equipment for introducing goods and services, caused to illegal use of other urban equipment. One of the important problems in Imam St. is a lot of stickers and posters on the walls and pavements. It is obvious that spending some part of incoming from billboard installation that is for beautification organization can be helpful for creating space and free facility for small job owners, also use of patterns for advertising billboards that their legs is suitable for advertisement installation and coating the walls with anti-adhesive for avoiding labeling advertising. In the other hand temporary advertising as common that every organization or institute set up banners on various occasions regardless of the urban landscape (that is general ownership) and at the end of ceremony these banners remain in the street, by approving a regulation that was about 
permitting agency and organization for temporary advertising and also specifying and defining the suitable spaces near governmental buildings for advertising seems to be solvable.

\section{REFERENCES}

1. Cullen, G. Urban land scape. University of Tehran, Tehran, Iran (2004).

2. Pakzad, J. Urban space design guidance. Maskan \& shahrsazi department, Iran (2006).

3. Rasooli, S \& Rahim Dokht Khoram, S. Create a good land scape in pedestrian routes. Journal of Armanshahr, vol 3. Tehran, Iran (2009).

4. Iveson, Kurt. Branded cities: outdoor advertising, urban governance, and the outdoor media landscape. University of Sydney, NSW (2006)

5. Ghalene Noei, M \& Madani, F. Positive \& negative visual disturbance in Chahar Bagh Abasi, Isfahan, Iran. National conference in Land scape, Iran (2010).

6. Bahreini, H. Analyzing of urban space. University of Tehran, Tehran, Iran (1999).

7. Hoseinion, S. Urban signboard reform. Journal of Shahrdariha, Tehran, Iran (2003).

8. Zahedi, A. The role of advertising boards in Shiraz land scape. National conference in Architecture, Culture \& Urban Management, Iran (2013).
9. Nooh Nejad, A. Urban advertising as lost Knowledge. Journal of Shahrdariha, Tehran, Iran (2009).

10. Iveson, Kurt. Branded cities: outdoor advertising, urban governance, and the outdoor media landscape. University of Sydney, NSW (2006)

11. Nooh Nejad, A. Urban advertising as lost Knowledge. Journal of Shahrdariha, Tehran, Iran (2009).

12. Ghalene Noei, M \& Madani, F. Positive \& negative visual disturbance in Chahar Bagh Abasi, Isfahan, Iran. National conference in Land scape, Iran (2010).

13. Iveson, Kurt. Branded cities: outdoor advertising, urban governance, and the outdoor media landscape. University of Sydney, NSW (2006)

14. Takahashi, M, Kazumi F, Tomomi Shimonaka, $\mathrm{M}$ and Kazuhiro S. Analysis of colors used on outdoor advertising in urban landscape: a case study in Osaka city (2007). SPIE; http:// dx.doi.org/10.1117/12.464635

15. Nastaran, M \& Hooshman far, S. Strategic planning in Urmia. Journal of Goghrafia \& motaleat mohiti, vol3. Iran (2010). 